\title{
The Impending Demise Of LIFO: History, Threats, Implications, And Potential Remedies
}

\author{
Brian W. Carpenter, Ph.D., University of Scranton, USA \\ Douglas M. Boyle, CPA, University of Scranton, USA \\ Yi Ren, Pd.D., University of Scranton, USA
}

\begin{abstract}
Since its approval by congress in 1939, the last-in-last-out (LIFO) inventory cost flow assumption has historically been utilized by a significant portion of U.S. companies for both tax and financial reporting purposes. However, despite its extensive use and wide acceptance in practice, the LIFO inventory method is currently endangered by two powerful movements that make its future existence far from certain. The first of these movements is the ongoing convergence of U.S. and international accounting standards. Whether future global harmonization of accounting practice come from continued convergence or outright adoption of international accounting standards, this harmonization poses a threat to the continued use of LIFO since LIFO is prohibited under international accounting rules. The second movement is grounded in governmental attempts to lessen the current federal budget deficit. The elimination of LIFO has been targeted as a way of reducing the deficit within the Obama administration's deficit reduction efforts. The momentum of these two threats to LIFO makes the topic of LIFO's future ripe for discussion. This study discusses the history of LIFO, illuminates the current threats the method faces, and outlines the most common remedies that have been proposed to mitigate the financial impact faced by companies that will be negatively affected by any such elimination of the method.
\end{abstract}

Keywords: LIFO; FIFO; Inventory Cost Flow; IFRS; Budget Deficit; Internal Revenue Code

\section{INTRODUCTION}

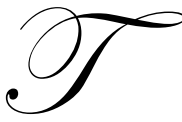

he continued use of the last-in last-out (LIFO) inventory cost flow assumption is currently in jeopardy. The cause of this accounting method's potential demise comes from two very divergent origins. The first threat comes from the desire by many in the accounting community to adopt international accounting standards. Since the use of LIFO is prohibited by the IASB, the potential adoption of international accounting standards presents a clear threat to the continued use of LIFO for U.S. companies. The second threat to LIFO's existence comes from the current budget crisis in the U.S. and the related need to increase tax revenues. Since the primary benefit of LIFO is the deferral of taxes, it stands to reason that it would be an attractive target for those who are seeking means of closing the current budget deficit. In recent years, such calls for LIFO's repeal for budgetary reasons have occurred with increasing frequency. As recently as September 2011, the Obama administration released a deficit reduction plan that included the elimination of LIFO. The call for LIFO's repeal was cited as potentially raising $\$ 53$ billion in tax revenue. These two phenomena represent a clear threat to the continued existence of LIFO as an acceptable inventory method.

The demise of LIFO would have significant ramifications for the business world, affecting financial and taxable income alike. The use of LIFO primarily originated as a means to lessen the tax burden of taxable entities, originally gaining Congressional approval in1939. The years following this initial approval saw its use extended to ever increasing populations of business enterprises. At times, the method itself evolved (i.e., Dollar Value LIFO) to continue to meet the desire of additional entities wishing to derive the tax benefits associated with its use. A survey 
of 600 largest publicly traded firms conducted by the American Institute of Certified Public Accountants (AICPA) indicated that $36 \%$ of surveyed firms use the LIFO inventory method ${ }^{1}$ It is clear that the LIFO cost flow assumption has become a staple of inventory accounting within the United States. And since current tax code requires companies to use LIFO for their financial reporting if they elect to use it for tax reporting, any repeal of LIFO would include important tax consequences for businesses. In short, if LIFO were to be repealed, its demise would represent a massive change in inventory accounting norms, and would have significant consequences on both the financial and taxable income for a sizeable number of U.S. companies.

\section{A BRIEF HISTORY OF INVENTORY ACCOUNTING IN TAX POLICY}

As early as 1919, the Treasury department permitted taxpayers to use only FIFO and average cost methods of inventory accounting. ${ }^{2}$ The use of LIFO was not permitted under any circumstances until 1938, when Congress enacted Section 22(d) of the Revenue Act of 1938, making LIFO available only to two industries with inventories of non-ferrous metals and leather hides. However, this initial inroad figuratively opened the floodgates. In less than a month, Senator Harrison and Representative Robert Doughton, Chairman of the Committee on Ways and Means, dissatisfied with the limitation of LIFO to only two industries, requested legislative change to expand the usage of LIFO. ${ }^{3}$ In less than one year, LIFO advocates managed to gain the approval of the LIFO method for every taxpayer with the passage of the Revenue Act of 1939.

\section{THE EFFECT OF FIFO VS. LIFO}

The initial resistance against the use of LIFO cost flow assumptions was likely based on a desire for cost flow assumptions to correspond with the actual physical flow of inventory. Such a presumption seems to be borne out by the initially approved inventory cost flow assumptions of FIFO and average cost. Both FIFO and average cost can easily be seen as corresponding with actual physical flows of actual inventory. Some companies might seek to sell their older stock first, which would mirror the assumptions inherent in the FIFO inventory method. Other companies might simply pool their inventory and simply sell inventory from this pool without regard to the specific item's acquisition date. This latter treatment would mirror the average cost method of inventory costing. Thus, the initially approved inventory costing methods largely reflected actual flows as seen in 'real life'. On the other hand, the LIFO cost flow assumption represents a clear departure from typical practice. It would be a rare for a company to specifically and consistently sell their most recently acquired inventory first. It seems clear that the predominant reason for interest in the LIFO method of inventory costing was for its ability to defer taxable income.

The cost of goods sold calculated under the FIFO inventory valuation method matches revenues against the cost of the earliest acquired inventory. Under the typical presumption of cost inflation, these earlier inventory costs would be the lowest within the inventory, thus matching revenue against the lowest possibly valuation of the product's cost. This in turn results in the highest possible valuation of gross profit. Accordingly, the main effects of FIFO accounting typically include the reporting of higher amounts of financial and taxable income resulting in higher tax liabilities.

Contrary to the matching found in FIFO, the LIFO method matches revenues against the most recently acquired items of inventory. Under the typical presumption of cost inflation, these most recent inventory costs would be the highest within the inventory, thus matching revenues against the highest possible valuation of the product's cost. This in turn results in the lowest possible valuation of gross profit. Accordingly, the main effects of LIFO accounting typically include the reporting of lower amounts of financial and taxable income.

Hence, the choice between FIFO and LIFO is usually presented as a choice between maximizing income (FIFO) or minimizing a firm's tax burden (LIFO).

\section{THE LIFO CONFORMITY REQUIREMENT UNDER IRC SECTION 472(C)}

From a reporting entity's perspective, there would be a natural temptation to choose different cost flow assumptions for the calculation of financial and taxable income. Differences in assumptions and techniques when calculating financial and taxable income are common, ranging from different methods of depreciation to differences 
in the timing of the recognition of many expenses and revenues. Accordingly, it would seem natural that businesses would seek to pick and choose different cost flow assumptions for the calculation of their inventory-related measures of cost and profit. And it would be obvious that the most attractive mix of cost flow assumptions would be the use of FIFO for financial income and LIFO for taxable income. Under the typical presumption of cost inflation, such a mix would result in the highest possible amount of reported financial income and the lowest possible amount of taxable income. This mix of cost flow assumptions however is prohibited by the conformity requirement found within Internal Revenue Code Section 472(c).

Internal Revenue Code Section 472(c) requires taxpayers who use LIFO for federal tax purposes to use the same method for book purposes. Unlike other inventory methods, the LIFO election is irrevocable and has to be used in all subsequent taxable years unless certain conditions arise. ${ }^{4}$ Thus, the decision regarding which cost flow assumption to use typically focuses on the contrast between higher reported income which comes at the cost of a higher tax obligation vs. lower reported income which comes with the benefit of minimizing current taxes. In short, FIFO is typically associated with higher income and higher taxes, while LIFO is typically associated with lower income and lower taxes. In actuality, it is more accurate to state that LIFO defers taxable income to the future, which increases the present value of the entity's net cash flows. However, it has become common practice to refer to this deferral as simply a reduction of current taxes.

The number of firms choosing to use LIFO methods of inventory valuation is noteworthy. It seems safe to presume that this selection is undoubtedly driven by the IRS's conformity rule. It can be said that management is acting in the firm's best interests by maximizing the present value of the firm's net cash flows in spite of the fact that it lessens reportable financial income. However, it should be noted that the resulting cost flow assumption often does not match the actual physical flows of inventory found in actual practice. It is this divergence between the assumed and actual flows of inventory that made approval of the LIFO method so difficult for firms to obtain in the past, and makes the method so vulnerable to extinction in the future.

\section{IFRS AND LIFO}

On August 27, 2008, the Securities and Exchange Commission (SEC) proposed a roadmap toward that could, if approved, culminate in the adoption of IFRS for publicly traded U.S. companies. The proposal stated its support for a single set of high quality global accounting standards. Under the proposal, the SEC would finalize their decision by the end of $2011 .{ }^{5}$ While a decision still not has been released, Hans Hoogervorst, Chairman of the IASB stated his belief that the direction of adopting IFRS has been established and there will be a global language with IFRS as the only candidate. ${ }^{6}$

As previously noted, the ultimate decision regarding whether such an adoption of IFRS will indeed occur is expected by the end of 2011. However, even if the SEC does not mandate the adoption of international standards, both the International Accounting Standards Board (IASB) and the Financial Accounting Standards Board (FASB) have been working hard to eliminate differences between their respective standards. Accordingly, the use of LIFO will be a topic of consideration for the accounting profession regardless of whether international standards are adopted or whether the two sets of rules simply converge.

If the SEC mandates the adoption of IFRS, LIFO users will be forced to abandon LIFO, because IFRS prohibits its use. If the SEC instead allows for the continued convergence of international and FASB rules, the LIFO technique still seems to have, at best, a very vulnerable future. It's unlikely that the favorable tax benefits associated with LIFO, especially in light of the method's failure to portray actual physical flows of inventory, will be seen as a persuasive argument for its continued existence in deliberations meant to achieve high quality standards of accounting. Further endangering the odds for LIFO's continued existence is the ever increasing focus on repealing LIFO as a means of mitigating the current fiscal deficit. For example, According to testimony of Dr. George A. Plesko (University of Connecticut School of Business) before the Committee on Finance United State Senate on June 13 2006, repealing LIFO would result in new tax revenues of around \$18 billion (based on 2004 data), given that his estimate does not include companies that are not publicly-traded. 


\section{THE FOCUS ON LIFO WITHIN THE BUDGETARY DEFICIT DEBATE}

The Obama Administration originally proposed repealing the LIFO technique for Federal tax purposes as part of their 2010 budget proposal. This initial attempt at eliminating LIFO was done in an inconspicuous manner as pointed out by Whitehouse in "Obama Budget Proposes LIFO Repeal Starting in 2010" Compliance Week, 2009 where it is stated that "the proposed budget offers no discussion of a plan to repeal LIFO except to include it as a line item among planned federal receipts." The proposal at that time projected that revenue generated from the repeal could reach up to $\$ 61$ billion through 2019 , with these revenues targeted for reduction of the federal deficit. ${ }^{7}$ However, after industry leaders and lobbyist expressed significant concerns related to the potential effects of the repeal, Congress quietly squashed the proposed repeal. ${ }^{8}$ However, LIFO's removal from the chopping block was not long-lived.

In September of 2011, the Obama Administration once again put the repeal of LIFO on the table, calling for its elimination in their proposed deficit reduction plan entitled "The President's Plan for Economic Growth and Deficit Reduction, Living Within Our Means and Investing in the Future." The repeal is also included in the Administration's 2012 proposed budget. This revived effort calls for the elimination of the LIFO methodology for Federal tax purposes for tax years beginning after December 31, 2012. The one time effect of this change would need to be recognized ratably over 10 years. ${ }^{9}$ The updated projection is that this change will generate revenues of approximately $\$ 53$ billion between 2012 through 2021 with the first $\$ 22$ billion being realized by $2016 .{ }^{10}$

While the President's latest proposal for LIFO repeal will not likely pass without a fight, the potential for the successful repeal of the method should not be underestimated. Calls for a reduction in the deficit have increasingly grown over time and seeking relief from corporate coffers could likely be seen as one of the more politically expedient and safe alternatives available for those looking for ways to close the gap. The elimination of LIFO represents one of the largest revenue increases proposed by the Administration and while it may be claimed as further imperiling small business and sectors of the economy currently facing job growth issues, it may more importantly be seen as a measure that poses relatively low political risk. It's clear that both proponents and opponents sense the seriousness of this proposed repeal and are preparing their best defenses of their respective positions.

As discussed in "Rush to Defend Tax Rule on Inventory and Profits" The New York Times, July 2011 "small businesses, manufactures, wholesalers, and retailers and oil companies would be especially hard hit". A LIFO Coalition has been formed representing over 20 lobbyists to work together to aggressively appeal to lawmakers to stop the repeal of LIFO. ${ }^{11}$

The argument for the elimination of LIFO as described by White House press secretary, Jay Carney, is that it would create a standard method for calculating the cost of goods sold for a company and simplify the tax code. In addition, the elimination would create a significant source of revenue to be used for deficit reduction with 40 percent of the impact being shouldered by the oil and gas industry. ${ }^{11}$

Parties against the elimination cite that the change would represent a significant hardship to certain industries such as manufacturing at a time when the President is trying to create jobs in those sectors. "The President's proposal would be devastating; it would increase our tax bill by tens of millions of dollars. Thousands of companies would be affected the same way", stated William Jones, vice chairman of O'Neal Industries ${ }^{11}$. In addition, the elimination represents a retroactive tax that would undo many years of tax benefit. Jade C. West, senior vice president of the National Association of Wholesaler-Distributors expressed his concern about the perceived fairness of the potential elimination by noting that "It's a huge retroactive tax, the government would tell companies that they must go back and recalculate the tax savings they have claimed for decades". ${ }^{11}$

Regardless of what side of the debate someone supports, it is clear that the discussion regarding the potential elimination of LIFO has reached a new level of seriousness with the likelihood of it ultimately being repealed being higher than at any other point in the method's history. 


\section{INTERNAL REVENUE CODE SECTION 481(A)}

It should be noted that a change from LIFO to any other method of inventory accounting will entail the additional issue related to the ensuing LIFO layer liquidation. Occasionally, LIFO is also referred to as FISH (fistin-still-here). This alternative acronym focuses on the method's impact on inventory values. When using LIFO, the inventory value is based on artificially low values since the valuation is based on the earliest acquired inventory. When an entity abandons LIFO as an inventory method, these older lower costs will work their way into the entity's cost of goods sold. Given the likelihood of lower cost of goods sold valuations, the possibility exists for increased reported income. Specifically, since gross profit is derived from sales minus cost of goods sold, recognizing a lower valuation for cost of goods sold (caused by the transfer of old inventory costs to cost of goods sold) would typically result in higher reported profits.

IRC Section 481(a) prescribes the rules to be followed in computing taxable income when taxpayers change their methods of accounting, such as inventory method changes. Generally, IRC Section 481(a) permits a taxpayer to deduct the entire negative adjustment (referred to as a "taxpayer-favorable" adjustment) in the year of change. However, Section 481(a) allows a net positive adjustment which the cumulative effect of the change increases the taxpayer's tax liability, to be taken into account over four years starting with the year of change. ${ }^{12}$ Accordingly, Section 481(a) may provide some relief for LIFO users by allowing them to spread their large spike in tax liability due to the effect of the change over four years. While this measure provides some relief, it will likely be viewed as insufficient to companies who have long relied on LIFO to lessen their tax burden. For example, examining a sample of 30 from largest publically traded companies with the greatest LIFO exposure, the Georgia Tech Financial Analysis lab reports that these firms' average pre-tax income and net income would be higher by $11.97 \%$ and $7.42 \%$, respectively if FIFO had been used by these firms in $2007 .{ }^{13}$ This increase in net income does not consider the full liquidation of the LIFO layer on the balance, which would result in a significant increase to net income in addition the 2007 year impacted, cited above. The relief provided by Section 481does little more than amortize the potentially significantly negatives consequences of LIFO layer liquidation over four years. This limited relief is likely to become a major issue for debate if, as anticipated, LIFO's existence continues becomes more threatened.

\section{PROPOSED REMEDIES FOR LIFO USERS IF LIFO IS REPEALED}

Following are few of the proposals that have been suggested as a means of helping to mitigate the burden faced by LIFO users if LIFO is ultimately disallowed as an inventory method.

1. Congress may amend or repeal IRC Section 472(c) which requires firms electing LIFO for federal tax to use the same method for financial reporting. ${ }^{14}$ In this case, firms can keep using LIFO for tax purpose, but use other inventory method for book purposes in order to meet potential adherence to IFRS requirements.

2. The Treasury Department may extend the period over which the positive adjustment (increases in tax liability) resulting from a change from LIFO may be amortized beyond the currently allowed four years. Or perhaps allow the resulting positive adjustment to be offset against net operating losses with carrybacks and carry forwards. ${ }^{15}$

3. Under the "The President's Plan for Economic Growth and Deficit Reduction, Living Within Our Means and Investing in the Future.", any one-time effect of the elimination of the LIFO layer could be recognized ratably over 10 years. ${ }^{9}$

While the first proposal would likely be readily welcomed by firms, it would be very unlikely to gain approval given that it would almost certainly significantly exacerbate the federal deficit as businesses would likely adopt LIFO en masse for tax purposes. The other proposals do little more than simply spread the increased tax liability over a range of time, which will not likely appreciably satisfy the concerns of the affected firms.

\section{CONCLUSION}

The threat to the continued use of LIFO for inventory evaluation has never been higher. Many in the accounting community believe that it's inevitable that we will ultimately adopt international accounting standards as 
represented by IFRS. However, even if such an adoption of IFRS is not forthcoming, it seems as though the ongoing efforts toward the continued convergence of FASB and IASB accounting rules could result in the same ultimate outcome. Adding to the perceived threat to LIFO has been the more recent calls for its repeal as a means of helping reduce the current budget deficit by up to $\$ 53$ billion through 2021. If the U.S. repeals LIFO, it can come in different forms and with different methods of offering relief to those companies affected by the change. It is possible that LIFO will be repealed for financial reporting, but be allowed for tax purposes. Or conversely, it is possible that it could be disallowed for tax purposes, but continue to be used for financial statement purposes. However, this latter possibility seems unlikely and if done would still effectively eliminate LIFO by eliminating its dominant reason for its use (i.e., the reduction of taxable income). The relief offered to those firms affected by any such repeal mainly comes in the form of amortizing the increases in taxable income resulting from LIFO layer liquidation over a period of time that may range from four to ten years depending on what proposal is implemented. It's not likely that the affected firms will find these measures as satisfactory and thus, the reason for the intensity of the current debate.

\section{AUTHOR INFORMATION}

Brian W. Carpenter, $\mathrm{PhD}$, is a professor of accounting at the Kania School of Management, University of Scranton, where he teaches upper level financial accounting courses. E-mail: bwc352@ scranton.edu

Douglas M. Boyle, MBA, CPA, CMA, is an assistant professor of accounting at the Kania School of Management, University of Scranton, where he teaches upper audit and accounting communication courses. E-mail: boyled2@scranton.edu. Corresponding author.

Yi Ren, $\mathrm{PhD}$, is a professor of accounting at the Kania School of Management, University of Scranton, where she teaches tax courses. E-mail: reny2@scranton.edu

\section{REFERENCES}

1. American Institute of Certified Public Accountants, Accounting Trends and Techniques, $62^{\text {nd }}$ ed. 2008, p. 159

2. Bahnson, P. R., and Miller, P. B. W., 2004. It's Time to Get Rid of LIFO Conformity: IASB's Move to Ban LIFO Deserves a Thoughtful Response. Strategic Finance, June 2004, pp. 43-47

3. Bloom, R., and Cenker, W. J., 2009. The Death of LIFO? Journal of Accountancy, January 2009

4. Comiskey, E.E., Mulford, C.W. and Thomason, J., 2008. The Potential Consequences of the Elimination of LIFO as a Part of IFRS Convergence. Working Paper, Georgia Tech Financial Analysis Lab, December, 2008 at www.mgt.gatech.edu/finlab

5. Fiscal Year 2010 Budget of The U.S. Government. Office of Management and Budget February 14, 2011

6. http://www.sec.gov/news/speech/2008/spch082708cc_ifrs.htm

7. IASB Chair address IFRS Foundation/AICPA conference, Boston, October, 2011

8. Internal Revenue Code Section 472(e)

9. $\quad$ Internal Revenue Code Section 481(a); Internal Revenue Manual 4.11.6.5.3 (05-13-2005)

10. Leone, M., 2010. Sucking the LIFO Out of Inventory. CFO, July 15, 2010; 26(6):27

11. Living Within Our Means and Investing in the Future, The President's Plan for Economic Growth and Deficit Reduction. Office of Management and Budget, September, 2011

12. Mock, R. P., \& Simon, A., 2009. The LIFO, IFRS Conversion: An Explosive Concoction. Tax Analysts, May 2009, 741-746.

13. Office of Tax Policy, List of Projects For Inclusion in the Next Revenue Act (Mar. 3, 1939)

14. Pear, R., 2011. Rush to Defend Tax Rule On Inventory and Profits. New York Times, July 13, 2011; 18.

15. Whitehouse, T., 2009. Obama Budget Proposes LIFO Repeal Starting in 2012. Compliance Week, May 19, 2009 